\title{
La mirada del extranjero. Reflexiones de José Ortega y Gasset sobre la psicología de los varones y las mujeres argentinas*
}

The Overview of a Foreigner. José Ortega y Gasset's Thinking about Psychology in Argentinian Men and Women

Recibido: enero 13 de 2014 | Revisado: julio 26 de 2014 | Aceptado: julio 17 de 2014

\author{
ANA Elisa Ostrovsky ** \\ LUIS AlBERTO MOYA *** \\ Universidad Nacional de Mar del Plata, \\ Buenos Aires, Argentina
}

doi:10.11144/Javeriana.upsy13-5.merj

Para citar este artículo. Ostrovsky, A. E., \& Moya, L. A. (2014). La mirada del extranjero. Reflexiones de José Ortega y Gasset sobre la psicología de los varones y las mujeres argentinas. Universitas Psychologica, 13(5), 1993-2002. http://dx.doi.org/10.11144/ Javeriana.upsy13-5.merj

Proyecto: Formación de Psicólogos. Enseñanza de la Historia de la Psicología y estudio de áreas de vacancia. En el marco del grupo de investigación: Historia, enseñanza y profesionalización de la psicología en el cono sur. Facultad de Psicología. UNMdP.

** Doctora en Psicología. Investigadora asistente CONICET (IIEGE-UBA). Universidad Nacional de Mar del Plata, Facultad de Psicología, Grupo de Investigación: "Historia, Enseñanza y Profesionalización de la Psicología en los países del Cono Sur de América". Dirección postal: Dr. E. Finochietto №480 Piso 1 dpto. K. Ciudad Autónoma de Buenos Aires CP: 1143. Argentina. Teléfono: (011) 43004767. Correo electrónico: anaelios@hotmail. com

**** Licenciado en Psicología. Becario de Investigación. CONICET. Universidad Nacional de Mar del Plata, Facultad de Psicología, Grupo de Investigación: "Historia, Enseñanza y Profesionalización de la Psicología en los países del Cono Sur de América”. Dirección postal: Brown 3066. Ciudad de Mar del Plata. CP: 7600. Provincia de Buenos Aires, Argentina. Teléfono: (0223) 15- 5129050. Correo electrónico: luigimoya@hotmail.com

\section{RESUMEN}

La psicología de los argentinos y argentinas fue una temática que atrajo la curiosidad de algunos observadores extranjeros. Entre los que visitaron la Argentina y escribieron sobre ella en la primera mitad del siglo XX, encontramos al norteamericano Waldo Frank, al alemán Keyserling y al filósofo español Ortega y Gasset, este ultimo viajó al país en tres oportunidades generando agudas observaciones acerca de la idiosincrasia de este pueblo. Dejó constancia de sus meditaciones en Intimidades, ensayo que forma parte de El Espectador. El presente trabajo tiene como objetivo analizar, a partir de dichos escritos, sus reflexiones acerca de las diferencias entre la psicología de los varones y las mujeres argentinas, en la conformación de la identidad nacional, entendiendo una asimetría fundamentada en la idea de nuestro país como un pueblo joven.

Palabras clave

Ortega y Gasset; psicología del argentino; diferencia sexual

\section{A B S T R A C T}

Argentinian psychology in both genders was a topic that attracted the curiosity of some foreign observers. Amongst the ones that visited Argentina and wrote about it in the first half of the twentieth century, we found the American Waldo Frank, the German Keyserling and the Spanish philosopher Ortega y Gasset. The latter travelled to the country in three opportunities, generating sharp observations about the idiosyncrasy of its people, recording his meditations in the essay "Intimidades", which is part of "El Espectador". The present work aims to analyze, from these writings, the reflections that the Spanish philosopher made regarding the differences between the psychology of Argentinian men and women. All of this shaped a national identity, understanding that the asymmetry is based on the idea of our country as a young nation.

Keywords

Ortega y Gasset; psychology of the Argentinian; sexual difference 


\section{Introducción}

En la segunda década del siglo XX en Argentina, contrabalanceando la hegemonía del naturalismo cientificista del primer decenio, se produce una reorientación de las concepciones psicológicas a partir de un movimiento en el cual $\mathrm{H}$. Bergson y M. Scheler se esgrimen como los modelos intelectuales que se deben seguir. En dicho viraje, fue fundamental la influencia de J. Ortega y Gasset, quien visitara nuestro país por primera vez en 1916.

Solidario con sus concepciones filosóficas e intelectuales produce un entusiasmo en el ambiente intelectual y universitario al renovar la discusión sobre las corrientes de pensamiento europeo contemporáneo, permitiendo de esa manera la recepción de nuevas perspectivas teóricas ligadas al neokantismo, la fenomenología de F. Brentano, W. Dilthey, E. Husserl, M. Scheler y las filosofías de la vida de Simmel. La conjunción de dichas filosofías fue considerada el marco general de los problemas teóricos en los que se moverá la llamada Generación del '14, que involucra a Ortega. En franca oposición al positivismo, se plasma una concepción vitalista fuertemente comprometida con la libertad individual, la axiología, la vida y la razón (Gil Villegas, 1996; Klappenbach, 1999; Marías 1948; Rossi, 2005; Terán, 2008).

Cabe destacar que el filósofo español, que como observáramos visitó la Argentina en tres oportunidades, engendró agudas observaciones acerca de la idiosincrasia de los argentinos y las argentinas en Intimidades, ensayo que formó parte de su obra El Espectador. Partiendo de dichas anotaciones, el objetivo del presente artículo es analizar, con base en estos textos, las reflexiones que Ortega realizó acerca de las diferencias entre la psicología de los varones y las mujeres argentinas en la conformación de la identidad nacional.

Ortega nace en 1883 en el seno de una familia representativa de las capas medias intelectuales europeas, que va a tener en el último tercio del siglo XIX una intensa actividad cultural y política. Dueña del diario El Imparcial, su familia hace que Ortega ya desde muy joven se interese por la gestión de proyectos culturales y editoriales (Babini, 1985).
Finalizada su tesis de filosofía en 1904, realiza estudios en Alemania, específicamente en la Universidad de Leipzig. En 1906, después de un semestre en Berlín, donde estudia con Simmel, se matricula en Marburgo, cuna del neokantismo, teniendo contacto con figuras como H. Cohen, P. Natorp y E. Cassirer (Ortega y Gasset, 1962a). Dicho clima cultural resultará decisivo para la configuración de su posicionamiento intelectual en relación a lo que él contemplaba en su tiempo. Dirá Ortega que el problema de su cultura contemporánea es la vivencia de un momento de acelerada modernización debido a la autonomización de las formas culturales, cuestión que plasma en su obra, muy leída en nuestro país, El tema de nuestro tiempo. A su parecer, dicho aceleramiento se produce a consecuencia de una oposición entre la vida y las formas, es decir entre la cultura subjetiva y la objetiva, conceptos propios de la filosofía alemana del siglo XIX (Gil Villegas, 1996).

De todas maneras, a los fines del presente trabajo, interesa especialmente la idea de que todo su pensamiento reconoce una proximidad con las ideas psicológicas (Carpintero, 1996; Carpintero \& Lafuente, 2007; Klappenbach, 1999; Ovejero, 2000; Sánchez-Barranco Ruiz \& Vallejo Orellana, 2005). En la Revista de Occidente, publicará varios artículos de psicología de corte histórico o cultural: el análisis sobre la soberbia española (Ortega y Gasset, 1923) o el ensayo sobre la psicología del español que escribiera Waldo Frank (Frank, 1925), los prólogos que el propio Ortega escribiera para las obras de Freud (Ortega y Gasset, 1922/1973), para la Introducción de las Ciencias del Espíritu de Dilthey (Ortega y Gasset, 1956/1983b) y Psicología de Brentano (Ortega y Gasset, 1935/1983a), entre otros. En definitiva, el énfasis en la psicología como ciencia del espíritu y el problema de la identidad psicológica de los pueblos aparecerán como una constante en los escritos e intereses de Ortega.

\section{Ortega en Argentina}

A partir de 1910, en Argentina, comienza una declinación del positivismo como consecuencia de diversos acontecimientos políticos y sociales. Hasta 
ese momento, había predominado la idea de un país crisol de razas con un destino de grandeza, crecimiento y bienestar. Los acontecimientos europeos, fundamentalmente la Primera Guerra Mundial con una Europa en conflicto generan un quiebre civilizatorio en todo el mundo occidental. En el mismo ámbito, la Revolución Rusa de 1917 plantea la idea de una expansión en relación con una fractura en el pensamiento liberal, con la instalación de otra construcción del Estado y la vida social que impacta en el resto del mundo (Terán, 2008). La instalación del primer gobierno surgido por sufragio universal, le otorga la presidencia a Hipólito Yrigoyen, un krausista, que se convierte en el primer presidente de Argentina electo por el pueblo, y dos años más tarde la reforma universitaria que se inicia en la Universidad de Córdoba tiene repercusiones en toda América Latina. Sus ideólogos Alejandro Korn y Coloriano Alberini, constituyen los representantes de lo que se ha dado en llamar reacción antipositivista, superación positivista o periodo de la psicología filosófica (Klappenbach, 2006).

En dicho movimiento, juega un rol decisivo la presencia de J. Ortega y Gasset, quien visita a Argentina por primera vez en 1916, invitado por la Institución Cultural Española, y dicta diversas conferencias públicas y un curso en la Facultad de Filosofía y Letras. Aunque todavía era un joven filósofo, ya venía precedido de un gran prestigio que le daba, sobre todo, su libro llamado Meditaciones del Quijote. Dichas conferencias serán importantes debido a que ingresa en un ambiente que aún aparecía signado por el positivismo, lo cual era considerado naturalmente ya un anacronismo. Entre los tópicos desarrollados en dichas conferencias se vislumbra una difusión de la obra de intelectuales que se situaban en las antípodas de lo que había primado hasta el momento, un marcado posicionamiento contra la parcialidad de la ciencia entendida en clave positivista. El filósofo, siguiendo a Husserl plantea a la filosofía como ciencia primera, una entronización de la conciencia como conciencia intencional y una superación de la concepción de verdad estrecha que presuponía el positivismo, entre otras cuestiones (Biagini, 1985; Campomar Fornieles, 2005; Terán, 2008).
El segundo viaje de Ortega y Gasset a la Argentina, realizado entre agosto de 1928 y enero de 1929, da lugar a varios ensayos recogidos en El Espectador VII y que compilará luego en su libro Meditación del pueblo joven. Entre ellos, los más conocidos La Pampa... Promesas y El hombre a la defensiva, inspirado por las filosofías de la vida, la fenomenología y el clima espiritualista antipositivista de la Europa de entreguerras, se focaliza en una reflexión y análisis de la psicología de los argentinos y argentinas. Cabe señalar que tales reflexiones se legitiman en una tradición de pensamiento de cuño centroeuropeo que tuvo como foco la psicología de los pueblos y los caracteres nacionales, gestada principalmente en Alemania desde mediados del siglo XIX, en publicaciones como la Revista de Psicología de los pueblos y de Filología de M. Lazarus y H. Steinthal y obras como los Elementos de Psicología de los Pueblos de W. Wundt (Guitart \& Ratner 2010). Dicha tradición, ya presente en las reflexiones de J. Herbart sobre la personalidad como fenómeno social y en los estudios del lenguaje como producto cultural de W. Humbolt, introduce el concepto de cultura como carácter o espíritu de una determinada nación, posibilitando el examen y consecuente estudio científico de los caracteres nacionales. Al respecto, articulándose con las problemáticas de los Estados modernos en procesos de emergencia o reorganización, surgirá una psicología que se pregunta por la tipicidad de lo nacional, no siendo casual la proliferación de reflexiones al respecto en diversas latitudes como las de Miguel de Unamuno, Rafael Altamira y el propio Ortega, en España (Carpintero, 2001; Fernández, 1998); Alcides Arguedas, en Bolivia; Alfredo Espinosa Tamayo, en Ecuador; Ezequiel Chávez, en México (Valderrama, 1986) y Carlos Octavio Bunge, Agustín García, José Ingenieros y José María Ramos Mejía, en Argentina (Vilanova, 2001).

Tales reflexiones, que conformaron una matriz de psicología social en cada uno de los lugares citados, comúnmente eran efectuadas por intelectuales nativos o residentes que estaban fuertemente comprometidos con los destinos de sus países y frecuentemente participaban de diversas formas en la política local. En cambio, Ortega analiza a 
la Argentina a través de la circunstancia europea, con los ojos de un extranjero, tal como lo hicieron desde sus propios marcos el norteamericano Waldo Frank y el alemán Hermann Alexander Keyserling (Frank, 1919/1929; Keyserling, 1933; Lojo, 2008). Así, desde su perspectiva eurocéntrica el filósofo español considera al país como un "pueblo joven", y en tanto tal, carente de ideas originales (GómezMartínez, 1983; Martínez de Codes, 1983; Molinuevo Martínez de Bujo, 1997; Zea, 1983). Dichos escritos reciben diversas respuestas que irán desde el más hondo rechazo hasta la defensa más sincera de sus aportes, que lo obligarán a publicar años después una autojustificación: Por qué he escrito 'El hombre a la defensiva' (Ortega y Gasset, 1962c).

\section{La psicología del varón argentino: entre el narcisismo y la inautenticidad}

En 1929, Ortega escribe su ensayo La Pampa... Promesas, donde ilustra una suerte de pasaje de la Pampa al alma del hombre argentino, invadido por dicho paisaje y su inagotable abundancia y concesión. Se pregunta si lo esencial de la vida argentina no es ser precisamente eso, una promesa. En La Pampa se encuentra la nada absoluta, frente a la tierra prometida ese lugar pasa a ser la tierra prometida, y si La Pampa es ser promesa, lo esencial de la vida argentina, dirá el filosofo, es ser promesa también. Dichas promesas incumplidas imprimirán una sensación de fracaso en América, más fuerte que en otras partes del mundo (Ortega y Gasset, 1929/1962a).

El alma criolla del hombre argentino está llena de promesas heridas, dice Ortega; el hombre no asiste a la vida efectiva, sino que está fuera de sí, instalado en la vida prometida. De esa manera, siente dolor en los miembros que le faltan y que, sin embargo, nunca ha tenido, actuando como un fracasado sin haber vivido la vida real. El criollo fracasa no por lo que hizo, sino por lo que teóricamente debía hacer (Ortega y Gasset, 1929/1962a). Sin embargo, Ortega va a identificar estos anhelos con la forma de existencia del argentino que él llama futurismo concreto, nutriéndose de sus ilusiones como si ellas fuesen la realidad. Este rasgo es un importante tema en las meditaciones ortegianas, ya que lo extiende al análisis de la personalidad general del argentino. Según Ortega, este futurismo no es un ideal común o una utopía colectiva, sino un extraño estado psicológico individual (Urbanski, 1968).

Desvelado con el tema, ese mismo año Ortega escribirá otro ensayo, como continuación del anterior, titulado El hombre a la defensiva, en el cual, empecinado en poder comprender la psicología del argentino, no comenzará con el paisaje de La Pampa hacia el alma nacional, sino que tomará un camino distinto que lo hará reflexionar previamente por la idea que tiene del Estado argentino, para luego a partir de allí pensar en la identidad vernácula: "Ese curioso desequilibrio entre la realidad social de la república con nombre de metal precioso y la idea de sí misma que su estado expresa me sirve de instrumento para penetrar en el alma individual del hombre argentino" (Ortega y Gasset, 1929/1962b, p. 23).

Así, para el autor, la Argentina presenta un fuerte Estado contrario a la espontaneidad social y cuya consecuencia es un desequilibrio con la realidad social. El país no posee una sociedad organizada, sino un Estado que aparece rígido, de grave empaque, ente sofocante de la individualidad, autoritario, gendarme de conductas, que organiza y señala proyectos, estableciendo diferencias e imponiéndose al resto de la sociedad. Este análisis le permite introducirse en la psicología del hombre argentino, uno de los objetos de análisis del presente trabajo.

La relación de los españoles con los argentinos invita a la más pronta y deslizante interpenetración, comparten el mismo idioma y dicha particularidad genera una rápida intimación. Sin embargo, afirma el filósofo, ese es el error. La velocidad con que el español se desliza hacia la intimidad del argentino sirve solo para que se produzca un choque violento con su superficie y se haga daño. El argentino está ausente o deja de sí mismo solo a su persona exterior, la periferia de su alma, lo que de esta da al entorno social. Su intimidad no está allí, es una máscara, no es un vivir espontáneo, no hay autenticidad: "La palabra, el gesto, no se producen como naciendo directamente de un fondo vital íntimo, sino como fabricado expresamente para el uso 
externo" (Ortega y Gasset, 1929/1962b, p. 25). La autenticidad, plantea Ortega, tiene lugar cuando las formas están en inmediata correlación con la vida. Sin embargo, en los argentinos dicha correlación no se produce debido a que el hombre está siempre a la defensiva, hipótesis central de su ensayo.

El hombre, preocupado en defender su propia persona, muestra su posición social o sus cargos como si fueran externos a él, sin vivirlos, los exhibe. Dicha preocupación exagerada por la posición social puede explicarse, desde la mirada orteguiana, a partir de la historia inmigratoria de nuestro país y la consecuente competencia por el ascenso social de dicha masa. Sumado a ello, está el hecho de que el argentino mismo no siente su conciencia tranquila respecto de la plenitud de los títulos y los emblemas con que ocupa aquel puesto social. Esto explica este estrato más externo de la estructura psicológica que Ortega ha llamado hombre a la defensiva.

Para el autor, el argentino no es incompetente, sin embargo nunca se ha adscripto a la actividad que ejerce, no la ha aceptado nunca como su destino vital. En el fondo, su actividad no es nunca vocación ni proyecto, allí es donde se compromete lo que uno es en un movimiento que va desde el impulso vital hacia las formas (Ortega y Gasset, 1929/1962b). La vocación es el proyecto que en todo instante es nuestra vida, sin embargo, afirma Ortega, el argentino no acepta dicha actividad como su destino vital, sino como etapa transitoria para el avance en su jerarquía personal. Audacia, apetito, falta de amor al oficio serán consecuencia de la injerencia del aplastante peso del Estado y la falta de una sociedad civil consolidada en sus tradiciones.

Así, el narcisismo del argentino no es la vanidad, sino la idea que tiene de sí mismo, lo que en él hay en germen, la promesa que trae como consecuencia una vida dedicada a la imagen de lo que puede ser. Y por estar tan preocupado por la promesa, inmerso en la fantasía, olvida la realidad y adopta una forma vacía de contenido. Esto lleva a Ortega a hablar del argentino como el "guarango".

La tragedia de narciso es que, ocupado exclusivamente en contemplarse, le ahoga su propia imagen, es decir, que no vive. De vivir, sería su imagen el viviente. Pero una imagen solo tiene una vida imaginaria, aparente, ficticia. Esto es lo grave en la psicología del argentino. No el egoísmo, no la vanidad. Su índole favorece sobremanera estos dos vicios, y no ocultaré que los casos más cómicos de vanidad que he conocido los he encontrado en la Argentina. (Ortega y Gasset, 1929/1962b, p. 46)

Procurar una correspondencia semántica estricta del vocablo "guarango", hoy vigente tal como se usaba en la década de 1920, conduciría a una forma de "presentismo", falacia histórica que presupone la inmutabilidad-la no historicidad-de los conceptos teóricos. En el contexto analizado, Ortega y Gasset define guarango como 'todo aquel que anticipa su triunfo, como la forma desmesurada de una propensión a vivir absorto en la idea de sí mismo'. Es el enorme apetito de ser algo admirable, superlativo, único, agresivo para defenderse y salvarse, haciéndose sitio para respirar, para poder creer en sí, dando codazos al caminar entre la gente para abrirse paso y crearse ámbito, siendo esta característica movida originariamente por un enorme afán de ser más y poseer, de esa manera, altos destinos (Ortega y Gasset, 1929/1962b).

Para concluir el análisis del hombre argentino, planteará el filósofo, que así como la sociedad argentina se deja envolver por un Estado demasiado presente y sólido, el argentino paraliza su vida suplantándola por la fantasía que posee de sí mismo.

Es preciso llamar al argentino al fondo auténtico de sí mismo, retraerle a la disciplina rigorosa de ser sí mismo, de sumirse en el duro quehacer propuesto por su individual destino. Sólo así podrá modificarse la moral colectiva, el tipo de valores preferidos, el standard de virtudes y modos de ser que, prestigiados, informen con fértil automatismo la existencia argentina. (Ortega y Gasset, 1962b, p. 305).

En consecuencia, dice Ortega, hace falta en $\mathrm{Ar}$ gentina una minoría que enseñe a aceptar el destino individual, que ponga como proyecto la autenticidad, superando de esa manera el guaranguismo, en donde se ocultan desviados los mejores resortes del alma y la psicología del argentino. 


\section{Ortega, la mujer argentina y la psicología de la diferencia entre sexos}

En las reflexiones psicosociológicas de Ortega, el argentino, que vive como anhelo de si mismo, añorando aquello que nunca tuvo, es particularmente el varón. Para el autor, en la observación social y la consecuente psicología de los pueblos, hay que analizar separadamente el aporte de lo masculino y lo femenino como elementos indisolubles. Asimismo, considera al descuido o desestimación de lo femenino como un error histórico que lleva a apreciaciones generales que poco ilustran sobre la verdadera idiosincrasia de una nación.

Es preciso que comencemos a corregir un inveterado error que se comete cuando se habla de la Psicología de una nación. Se dice: el francés o el alemán o el español es así o de este otro modo. Pero ide quién se habla?, ¿del varón o de la mujer?, ipor qué cerrarse a la evidencia de que en cada país los dos sexos se diferencian mucho más de lo que corresponde a su diferenciación sexual?... (...)... Si se olvida esto no se puede llegar a comprender el alma de un pueblo que resulta de la colaboración de dos almas distintas. Y como todo compuesto, sólo se entiende cuando se aíslan sus elementos y se los analiza por separado. (Ortega y Gasset, 1929/1962b, p. 23)

Es por ello que, teniendo dicho recaudo epistemológico como telón de fondo, Ortega al estudiar al argentino, se detiene y diferencia al varón de la mujer argentina, la que particularmente aborda en sus Meditaciones de la criolla. Dicho ensayo es fruto de las emisiones radiofónicas que desplegó en su tercer viaje a Buenos Aires, en 1939, en las que intentó establecer el tipo social femenino que constituía la criolla (Ortega y Gasset, 1939a/1962c).

Cabe destacar que el filósofo español en otros pasajes de sus obras, particularmente las que tuvieron como tópico al amor, desarrolla una psicología de la diferencia entre sexos. En el último apartado de su Rebelión de las masas, separa a lo masculino de lo femenino de manera asimétrica, en tanto la mujer necesariamente requiere al varón para ser definida como tal, mientras que este, desde su óp- tica, puede definirse en sus más importantes logos como el arte y la ciencia con independencia de su relación con las mujeres (Ortega y Gasset, 1930). En otros textos, pareciera casi autobiográficamente preguntarse por el tipo de hombre que atrae a las mujeres y por la esencia del Don Juan, ser que lejos de seducir y atrapar a incautas damiselas, es elegido activamente por ellas por sus cualidades. Así, en Amor en Stendhal, afirma sin vueltas el papel activo de las mujeres en la configuración del personaje: "Don Juan no es el hombre que le hace el amor a las mujeres, sino el hombre a quien las mujeres le hacen el amor" (Ortega y Gasset, 1939b/1940a, p. 19). En sintonía, en su trabajo sobre la psicología del hombre interesante, subraya al prototipo del personaje de Tirso de Molina como un ideal masculino por excelencia: "Los hombres pueden dividirse en tres clases: los que creen ser Don Juanes, los que creen haberlo sido y los que creen haberlo podido ser pero no quisieron" (Ortega y Gasset, 1939c/1940b, p. 162). En otros textos, analizando la esencia de los sexos, pareciera que la actividad femenina señalada en líneas precedentes se despliega con la finalidad de entregarse. Desde su óptica, la naturaleza de la feminidad es la entrega, una mujer realiza su destino cuando entrega su persona a otra persona. Como consecuencia, todo lo demás que la mujer hace o es, todos sus estandartes y sus movimientos, para el filósofo español, tiene un carácter adjetivo y derivado (Ortega y Gasset, 1939d/1940c). En franca complementariedad, el instinto radical de la masculinidad, es el impulso de apoderamiento; el apoderarse de otra persona como eje de la vida del varón. De esta forma, la relación entre los sexos en los desarrollos orteguianos pareciera siempre de complemento, de armonización de los opuestos. En su análisis de la figura de Salomé, lo explicita de esta forma:

Existe pues, una armonía preestablecida entre hombre y mujer; para esta, vivir es entregarse; para aquel, vivir es apoderarse y ambos sinos, precisamente por ser opuestos, vienen a perfecto acomodo... (...)... El conflicto surge cuando en ese instinto radical, de lo masculino y lo femenino se producen desviaciones e interferencias. (Ortega y Gasset, 1939d/1940c, p. 138) 
Si bien el autor menciona que ambos tipos no se encuentran en estado puro, y que en la realidad se dan combinaciones de lo masculino y lo femenino en una suerte de armonización de los principios orientales del ying y el yang, afirma que es una división que quiere mantener como tipo ideal. Así, Ortega, renegando de la tradición empirista "según el cual todo acontece al azar y sin forma unitaria" (Ortega y Gasset, 1939d/1940c, p. 173), afirma que los principios de masculinidad y feminidad corresponden a una división ideal, cada uno con sus características y sus fines rectores. Por supuesto que hay combinaciones, sobre todo en lo que el autor denomina "sexualidad psicológica", pero estas son combinatorias de elementos claramente definibles que subyacen a todas las manifestaciones de las personas. La tarea del psicólogo no es describir tales manifestaciones comportamentales ni hacer estadística con ellas, sino escudriñar los verdaderos resortes, a menudo ocultos para el observador desprevenido: "Por eso el psicólogo tiene que transformarse en buzo y sumergirse bajo la superficie de las palabras, de los actos, de los pensamientos del prójimo, que son mero escenario. Lo importante está detrás de todo eso" (Ortega y Gasset, 1939e/1940d, p. 77).

Volviendo a la Argentina, vemos que el autor, sumergiéndose en observación sobre la diferencia sexual de los pueblos, luego del complicado panorama que le adscribe al varón, se detiene a reflexionar sobre la mujer argentina, la que denomina criolla, señalando el uso que le va a dar a dicha palabra que poco tiene que ver con el verdadero linaje de la mujer, su pasado indio o su lugar de nacimiento. Las criollas son las mujeres americanas, en este caso las argentinas, y de las presuntas raíces españolas y lusitanas en su amalgama con los pueblos originarios, solo quedan rasgos psicológicos y no lazos necesariamente sanguíneos. En efecto, para Ortega la criolla es un "tipo" de mujer creado poco a poco en lo colectivo: cada una de las criollas depositaron sus invenciones y esa norma o pauta extrapersonal se trasladó a las mujeres americanas. A partir de dicho mecanismo histórico, podrían hacerse presente los particulares rasgos de la princesa inca en la porteña de padres italianos sin una gota de sangre peruana.
Haciendo dicha salvedad, el autor español se lanza a estudiar elogiosamente a la mujer criolla argentina que él conoce y es específicamente la porteña ${ }^{1}$.

\section{La "criolla": vehemencia, autenticidad, gracia y molicie}

Para el filósofo, el análisis de la mujer es un asunto serio, que atañe a la historia universal y su elemento femenino otrora descuidado. Su reflexión poco tiene que ver con lo que él denomina la "moda" de hablar de las mujeres. Así, adjetivando, se zambulle hacia las profundidades de la criolla -la criolla porteña casi prototípica de las demás- cuando afirma burlonamente que Buenos Aires es algo así como el frigorífico de las criollas, que las congela primero y las exporta después (Ortega y Gasset, 1939a/1962c).

El primer rasgo que conforma su tipo es la vehemencia. Sostiene que la argentina es vehemente, tenaz y persistente, como quizás lo fue la española y la portuguesa de los siglos XVI y XVII, no las actuales ni tampoco las inertes mujeres del norte de Europa. El estado de las criollas es el "lujo vital", no importa su riqueza o pobreza, para Ortega, la vehemencia es una firmeza "de piel suave y sabor dulce" que no nace del rencor, sino de la energía misma del vivir. Como en la mujer que "le hace el amor" al hombre interesante, como la que elige al Don Juan, la mujer prototípica de la fuerza vital de lo femenino, en Ortega, se encarna perfectamente en la criolla argentina.

De la mano de la vehemencia, Ortega ubica la espontaneidad; la criolla porteña sería el grado máximo de espontaneidad femenina. Ella es permanente autenticidad, lo contrario de la criatura convencional y amanerada, que se comporta copiando modelos ajenos. Dicha imagen, distinta a la imagen femenina de su Divagación ante el retrato de la marquesa de Santillana donde afirma que "La mujer vive en perpetuo azoramiento, porque vive en perpetuo encubrimiento de sí misma" (Ortega y Gasset, 1939f/1940e, p. 125), es contraria a la

1 En Argentina se denomina mujer porteña a la nacida en la zona de la cuenca del Rio de la Plata, particularmente en la ciudad de Buenos Aires. 
originalidad. Ello se observa en que para el autor dicha espontaneidad si bien rechaza lo preestablecido desde fuera como imposición, tampoco deriva en lo que denomina "mujer original", fuera de las convenciones sociales de "extravagantes altitudes" y "complicadas lejanías". El filósofo español subraya particularmente que la criolla no se evade de los usos sociales, se encuentra asentada tranquilamente en la cotidianeidad, lejos de la originalidad que "asusta, espanta y enfría”. En su La elección en amor aparece también esta ubicación de la mujer tipo, en lo cotidiano.

Ahora bien, donde lo cotidiano gobierna es siempre un factor de primer orden la mujer, cuya alma es en un grado extremo cotidiana. El hombre tiende siempre más a lo extraordinario, por lo menos sueña con la aventura y el cambio, con situaciones tensas difíciles, originales. La mujer por el contrario, siente una fruición verdaderamente extraña por la cotidianidad. (Ortega y Gasset, 1940d, p. 109)

Allí sostiene además que la mujer "sólo es feliz ocupada en faenas cotidianas, sea zurcir ropa blanca sea acudir al danzing" (p. 110). Dentro de dicho ámbito doméstico, cotidiano, poco extravagante, es donde chispea la originalidad de la criolla, quizás con su desenfado y sus comentarios simpáticos más que con posicionamientos rupturistas como los de su porteña amiga Victoria Ocampo ${ }^{22}$, con quien mantuvo una compleja amistad llena de encuentros y desencuentros (Queirolo, 2002).

Vehemencia y espontaneidad derivan en la tercera cualidad de la criolla, la gracia, ángel que se manifiesta en sus ademanes, posturas, expresiones y en todos sus roles: de madre, esposa, hermana, e hija. Juntamente con la gracia, como último y cuarto elemento constitutivo de la mujer criolla tipo, Ortega ubica a la molicie. Para ejemplificarlo invita a sus oyentes a imaginar un objeto dotado de innumerables y minúsculos muelles, con fina y enérgica elasticidad que ceden al apoyarse sobre

2 Victoria Ocampo (1890-1979): escritora, intelectual, ensayista, traductora y mecenas argentina. Fundadora de la prestigiosa revista Sur. ellos, pero no se rompen y vuelven a la posición original. Así, con un poco de suavidad y de firmeza combinaría la criolla perfectamente los atributos de los opuestos: podría ser un poco dura, de talla, de piedra y también etérea, irreal y fantasmática; podría ser mujer de entereza sin renunciar a la levedad del romanticismo.

\section{Palabras finales}

La psicología de los pueblos, temática presente desde el nacimiento de la psicología como disciplina autónoma desde el último cuarto del siglo XIX, en sus múltiples reflexiones, ha estudiado las mentalidades y los sentires de los pueblos, de la mano de la necesidad de estos de pensarse a sí mismos. Dicha necesidad, motivada por cambios históricos de diverso cuño: sociales, económicos, y culturales, generalmente ha hallado su encarnadura en los mismos habitantes del suelo: psicólogos, juristas, filósofos, médicos, habitantes que por su particular posicionamiento social se sintieron compelidos a dicha tarea. No obstante, en ocasiones, tales reflexiones surgen desde el extranjero, aquel teórico que con la mirada del antropólogo clásico, vive en el suelo y examina minuciosamente los comportamientos y sentires de sus habitantes. José Ortega y Gasset, en sus tres viajes a la Argentina resalta la importancia de la duración de sus estadías en Buenos Aires y legitima en dicha temporalidad vivida la rigurosidad de su examen psicológico de los tipos locales. Así, se zambulle en lo que él denomina las profundidades, los resortes anímicos de las personas que explora, desde sus conferencias y visitas hasta el golf y la calle.

$\mathrm{Al}$ respecto, señalamos en el autor la relevancia de la diferenciación entre los aportes masculinos y femeninos en la conformación de la psicología del argentino. Su rescate de las mujeres, el señalamiento de su ineludible participación en el movimiento universal de la historia lo empuja epistemológicamente a diferenciar ambos elementos. Así, separando los términos de su análisis, llama la atención lo asimétrico de sus consideraciones sobre la intervención de lo masculino y femenino en el tipo argentino. Los varones a sus ojos aparecen presos de sus 
apariencias, enmarañados en demostrar lo que no son y añorar lo que nunca fueron, guarangos, enrostradores de cucardas, siempre de paso. Las mujeres, en contraposición, emergen encarnando su ideal femenino: el de la mujer doméstica pero inteligente, romántica pero estoica, grácil pero espontánea. La criolla recibe sus alabanzas porque no es inerte, pero tampoco rupturista y no es tan extravagante como para desafiar sus roles convencionales y arrojarse a provocar los disgustos y las repelencias que provocaría por ejemplo una feminista. Dicha asimetría entre varones y mujeres quizás podría explicarse en su encuadramiento de la Argentina como un pueblo joven, un pueblo que aún no puede aportar originalidad y novedad, elemento esencialmente masculino, pero que sí puede, en su carácter conservador y detenido, retener acaso aquellas características femeninas que, según Ortega, están siendo olvidadas por sus congéneres europeas. Así, más idealizada que examinada, la psicología de la criolla aparece como la psicología del visitante español en enamoramiento y rivalidad con sus contrincantes de donjuanismo, acaso los guarangos y oportunistas varones argentinos.

\section{Referencias}

Biagini, H. (1985). Ortega en la Argentina. Todo es Historia, 220, 38-49.

Campomar Fornieles, M. (2005). Ortega y Gasset: un viajero imaginario por la Argentina. Circunstancia: Revista de Ciencias Sociales del Instituto Universitario de Investigación Ortega y Gasset, 6(3). Recuperado de http://www.ortegaygasset.edu

Carpintero, H. (1996). Historia de las ideas psicológicas. Madrid: Pirámide.

Carpintero, H. (2000). Esbozo de una psicología según la razón vital. Madrid: Real Academia de Ciencias Morales y Políticas.

Carpintero, H. (2001). La psicología y el "problema de España”. Una cuestión de psicología social. Psicothema, 13(2), 186-192.

Carpintero, H., \& Lafuente, E. (2007). El método histórico de las generaciones: el caso de la psicología española. Revista de Historia de la Psicología, 28(1), 67-85.
Fernández, J. Q. (1998). Fundamentos teóricos de la" Psicología del carácter español” de D. M. de Unamuno. Esbozo de una" Psicología de los pueblos". Revista de Historia de la Psicología, 19(1), 43-79.

Frank, W. (1929). Nuestra América. Buenos Aires: Babel. (Trabajo original publicado en 1919)

Frank, W. (1925). El español. Revista de Occidente, 10(28), 39- 50.

Gil Villegas, F. (1996) Los profetas y el Mesías. Lukács y Ortega como precursores de Heidegger en el Zeitgeist de la modernidad (1900-1929). México: Fondo de Cultura Económica.

Gómez-Martínez, J. L. (1983). Presencia de América en la obra de Ortega y Gasset. Revista Quinto Centenario, 6, 125-160.

Guitart, M. E., \& Ratner, C. (2010). Historia, conceptos fundacionales y perspectivas contemporáneas en psicología cultural. Revista de Historia de la Psicología, 31(2), 117-136.

Keyserling, H. (1933). Meditaciones suramericanas. Madrid: Espasa Calpe.

Klappenbach, H. (1999). La recepción orteguiana. Alberini y la renovación de la psicología argentina a partir de los años veinte. Revista de Historia de la Psicología, 20 (1), 87-95.

Klappenbach, H. (2006). Periodización de la psicología en Argentina. Revista de Historia de la Psicología, 27(1), 109-164.

Lojo, M. (2008). Los viajeros intelectuales: Keyserling y Frank, en Historia de una pasión argentina de Eduardo Mallea. Taller de Letras, 42, 73-90.

Marías, J. (1948). Ortega y la idea de la razón vital. Madrid: El Viento Sur.

Martínez de Codes, R. (1983). Ortega y la Argentina. Revista Quinto Centenario, 6, 53-86.

Molinuevo Martínez de Bujo, J. (1997). Ortega y la Argentina. México: Fondo de Cultura Económica.

Ortega y Gasset, J. (1923). Para una topografía de la soberbia española. Revista de Occidente, 3, 265- 280.

Ortega y Gasset, J. (1930). La rebelión de las masas. Madrid: Revista de Occidente.

Ortega y Gasset, J. (1940a). Amor en Stendhal. En Estudios sobre el amor (pp.11-70). Buenos Aires: Espasa Calpe. (Trabajo original publicado en 1939)

Ortega y Gasset, J. (1940b). Para una psicología del hombre interesante. En Estudios sobre el amor (pp.159. 
173). Buenos Aires: Espasa Calpe. (Trabajo original publicado en 1939)

Ortega y Gasset, J. (1940c).Esquema de Salomé. En Estudios sobre el amor (pp.137-146). Buenos Aires: Espasa Calpe. (Trabajo original publicado en 1939)

Ortega y Gasset, J. (1940d). La elección en amor. En Estudios sobre el amor (pp.71-104). Buenos Aires: Espasa Calpe. (Trabajo original publicado en 1939)

Ortega y Gasset, J. (1940e). Divagación ante el retrato de la marquesa de Santillana. En Estudios sobre el amor (pp.121-136). Buenos Aires: Espasa Calpe. (Trabajo original publicado en 1939)

Ortega y Gasset, J. (1962a). La Pampa. Promesas. En Meditación del Pueblo Joven (pp. 2-14). Madrid: Revista de Occidente. (Trabajo original publicado en 1929)

Ortega y Gasset, J. (1962b). El hombre a la defensiva. En su Meditación del Pueblo Joven (pp. 15- 51). Madrid: Revista de Occidente. (Trabajo original publicado en 1929)

Ortega y Gasset, J. (1962c). Meditación de la criolla. En Obras completas (Vol. 8, pp. 413-445) Madrid: Revista de Occidente. (Trabajo original publicado en 1939)

Ortega y Gasset, J. (1973). [Prólogo a la primera edición]. En S. Freud, Obras completas (3. - ed., Vol. 1, pp. 9-10). Madrid: Biblioteca Nueva. (Trabajo original publicado en 1922)

Ortega y Gasset, J. (1983a). [Prólogo]. 'A Psicología', de Francisco Brentano. En Obras completas (Vol. 6, pp. 337-338). Madrid: Alianza. (Trabajo original publicado en 1935)

Ortega y Gasset, J (1983b). [Prólogo]. Introducción a las ciencias del espíritu. Wilhelm Dilthey. En Ob- ras completas (Vol. 7, pp. 57-67). Madrid: Alianza. (Trabajo original publicado en 1956)

Ortega y Gasset, J., \& Molinuevo, J. L. (Ed.). (1996). Meditación de nuestro tiempo. Las conferencias de Buenos Aires, 1916 y 1928. México: Fondo de Cultura Económica.

Ovejero, A. (2000). Un pensador pre-postmoderno altamente fértil para la Psicología postpositivista del siglo XXI. Historia de la Psicología, 21(2), 35 52 Queirolo, G. (2002). Diálogos acerca de lo femenino: Victoria Ocampo y José Ortega y Gasset. Cyber Humanitatis, 23.

Rossi, L. (2005). La subjetividad en los argentinos contemporáneos, 1920-1960. Buenos Aires: JVE Ediciones.

Sanchez-Barranco Ruiz, A., \& Vallejo Orellana, R. (2005). Ortega y Gasset, la psicología y el psicoanálisis. Revista de la Asociación Española de Neuropsiquiatría, 25(95), 121-137.

Terán, O. (2008). Historia de las ideas en la Argentina. Diez lecciones iniciales, 1810-1980. Buenos Aires: Siglo XXI.

Urbanski, E. (1968). La pampa y los porteños en la reciente interpretación argentina. Asociación Internacional de Hispanistas. Actas III. (En línea). Disponible en http://cvc.cervantes.es/literatura/aih/pdf/03/ aih_03_1_ 096. pdf

Valderrama, P. (1986). El carácter nacional y la psicología de los pueblos en América Latina. Revista Latinoamericana de Psicología, 18(1), 87-107.

Vilanova, A. (2001). El carácter argentino. Los primeros diagnósticos. Mar del Plata: Universidad Nacional de Mar del Plata.

Zea, L. (1983). Presencia cultural de Ortega en Hispanoamérica. Revista Quinto Centenario, 6,13-36. 